\title{
The Murray-Darling Basin plan and public policy failure: a transaction costs analysis
}

\author{
A. Loch \& R. McIver \\ School of Commerce, University of South Australia, Australia
}

\begin{abstract}
Australian governments have increasingly relied upon water markets to reallocate water between consumptive and environmental uses. Such markets appear appropriate for facilitating consumptive users' adjustment to factors such as drought. However, where effective institutional arrangements remain elusive, markets alone will be insufficient to provide environmental water reallocation. A basin-wide planning approach represents the Australian Government's strategy to replace diverse state water-sharing plans, address over-reliance upon markets and take in hand institutional failure. Given its previous inability to deliver environmental reallocation, this paper applies McCann and Easters' transaction cost typology and Williamson's transaction costs analysis framework approach to evaluate alternative Basin Plan institutional structures, and determine if efficient institutional approaches to water-reallocation are possible. We find that while efficient institutional alternatives are feasible, careful attention to design is required. This involves consideration of environmental property rights, statefocused incentives and appropriate use of existing market institutions.

Keywords: transaction costs, environmental water, Murray-Darling Basin.
\end{abstract}

\section{Introduction}

Water managers around the world may be viewing recent moves by Australia to introduce a basin-wide environmental plan with interest, especially where their own concerns cover trans-boundary issues. Arguably, Australia has been heavily constrained by decisions made in the past, but we contend that the Australian government has not yet formulated the capacity, established appropriate incentives or achieved the effective structural design parameters needed to implement an efficient basin-wide plan in the Murray-Darling Basin (MDB). 
This view is based on two historical tensions, each a path-dependent result, impacting on the discussion and management of scarce MDB water resources.

First, there continues to be a significant imbalance between MDB consumptive and environmental water property rights, leaving insufficient water for ecosystem sustainability. This imbalance has focused MDB water managers' attention, like others around the world, on instruments to reduce the consumptive pool and transfer water to the environment. The Basin Plan instrument aims to recover between 2,400 and 3,200 GL for the environment [1], and a program of entitlement purchasing from irrigators has narrowed the gap between this target and the amount recovered so far. However, the inability to prioritise environmental above socio-economic needs continues to present issues for the Murray-Darling Basin Authority (MDBA) to address, and threatens to undermine the final Basin Plan targets. Second, there is a divergence of water powers in Australia between the state and federal governments, resulting from the states being granted ownership of water resources. Each state has invested in water storage infrastructure, delivery management regimes and water-sharing plans to identify and cater for consumptive and environmental water needs, but they have not progressed quickly enough toward sustainable environmental flows in the MDB [2]. While a Basin Plan allows the federal government to play a larger role in the support, contracting, monitoring and enforcement of environmental flows it would still rely heavily on state processes to deliver environmental outcomes. To protect water infrastructure investment returns, and avoid forfeiting state powers, it is possible that the states may continue to directly or indirectly oppose the Basin Plan increasing total reform transaction costs.

Transaction costs include expenses associated with market organisation and participation in, or the implementation of, government policy [3]. In the Basin Plan, successfully shifting water from consumptive to environmental uses should involve low transaction costs. Where transaction costs are incurred, they should support efficiency-enhancing institutional change and the promotion of least-cost paths to target outcomes - subject to path-dependent characteristics inherent to the system under consideration. Until these tensions are successfully addressed, the challenges and transaction costs associated with creating an efficient Basin Plan are likely to remain high. In particular, trying to consolidate government, irrigator and environmental needs through a prescriptive Basin Plan may result in transaction costs that are too large to efficiently and effectively implement. Importantly, scope for state planning changes and uncertainty remains high before the Basin Plan is finalised. Further, the final plan must be evaluated using best available science and economics. Thus, from an economic transaction cost perspective, efficient Basin Plan governance structures should minimise the sum of water reallocation transaction costs, and deal best with the effects of reallocation hazards. Herein we apply two transaction cost analysis techniques to evaluate the institutional changes associated with water reallocation in the MDB. In particular, we consider transaction costs associated with: i) the initial assignment of property rights; and ii) market-based versus rules-based environmental flow allocations. To achieve this evaluation we apply McCann 
and Easter's [4] transaction cost typology [TCT] to review and synthesise previous MDB water reform and reallocation approaches, and Williamson's [5] transaction cost analysis [TCA] framework to identify potential economically efficient Basin Plan institutional structures. Williamson's TCA framework provides a suitable analysis structure for water reallocation, particularly those via market transactions following an initial assignment of property rights. This is because TCA involves comparing critical dimensions on which the transaction costs differ, and examines the economising characteristics of alternative institutional approaches. This paper uses TCT and TCA techniques to suggest an optimised Basin Plan approach for the reallocation of water between consumptive and environmental uses. We are interested in determining whether transaction cost analysis can assist economists to identify an efficient institutional approach for structuring the Basin Plan. Such analysis also helps us to understand whether alternative Basin Plan structures offer the Australian government an opportunity to overcome past policy failures, and settle the tensions discussed above. In addition, the analysis assists determinations of whether the Australian government can provide the structures and necessary coordination to implement a Basin Plan, or whether further government and public policy failure may eventuate. Ultimately the paper provides normative arguments about efficient Basin Planning arrangements given prevailing property rights and environmental planning regimes in the MDB, together with insights for future water policy arrangements.

\section{Transaction costs in water reform}

The study of transaction costs offers a useful institutional structure comparison tool [6]. Therefore, to assist in the understanding of possible public policy barriers to effective and efficient planning structures in the MDB, as well as elsewhere around the world an application of transaction costs analysis is appropriate. There are a number of transaction costs specific to the issue of water reallocation and reform. Several are present in the Australian context because water often violates the conditions under which economic theory suggests markets can provide (exact) inducement and encourage efficient resource use [7]. For example, by nature water is lumpy requiring significant and on-going infrastructure investment by users to assist in its storage, delivery (including losses) and administration.

Water use and reallocation also entails large information asymmetry, negotiation and legal agreement costs, which can motivate strategic behaviour on the part of suppliers or users. This is because water use is often non-rival. Reducing information asymmetry thus requires substantial transaction costs, which must be overcome to avoid delaying or preventing reallocation altogether. Finally water use imposes externality costs, i.e. use of the resource by one party affects or is affected by use of the resource by another party. Water reform in the MDB is often characterised by information asymmetry between the federal and state governments. There have also been significant prior state investments in infrastructure and institutions that create static transaction costs for water 
owners, managers and users. Further, many early water reform policies and programs did not achieve significant reallocation between consumptive and environmental water users.

\subsection{MDB water reform using TCT categorisation}

To analyse early MDB water reform and reallocation policies and programs we first apply the TCT approach as a means of categorising associated transaction costs. Categorisation using TCT allows transaction costs to be grouped in relation to: 1) research and information collection; 2) enactment or litigation; $3)$ process design and implementation; 4) support and administration; 5) contracting; 6) monitoring or detection and; 7) enforcement of agreements or conflict resolution. Such analysis helps us identify important institutional reforms, their outcomes, and relevant types of associated transaction costs - as well as MDB water reform transaction costs that are static (difficult to change without substantial further costs being incurred) or dynamic (open to institutional or adaptive change without substantially high additional costs being incurred). MDB water reform is aimed at providing environmental water stocks, and the transaction costs associated with that reform have been significant. For example, initial environmental-right-enactment transaction costs were driven by the Council of Australian Governments (COAG) Agreement reforms [8]. These reforms encouraged states to recognise the environment as a legitimate water user and to prioritise environmental rights via water sharing arrangements. The agreement was also an early example of water reform contracting transaction costs between the parties. Further, an example of large information gathering transaction costs can be identified in the 1993 audit of the MDB river systems, which that concluded flows to sea were a fraction of their natural levels and that drought effects were present in 60 per cent of years compared with five per cent naturally [9]. Such information was used to constitute water-sharing requirements as a basis for water-sharing plans by each of the MDB states. The development of state water sharing plans provide examples of advanced transaction cost types in the water reform process, associated with early forms of establishment and monitoring of environmental outcomes, enforcement of sharing arrangements and conflict resolution arrangements between affected parties.

For state water-sharing plans to work a fixed extractive base close to current levels was required. In 1997 a cap on further water extraction was established at the 1993/94 level of development. The cap was not designed to establish environmental needs; instead it prevented further resource degradation. Water markets were institutionalised to assist users reallocate water among themselves under the new cap conditions. Establishment of water markets represent enactment/litigation, design/implementation and support/administration transaction costs, borne mostly by the states. This was consistent with a worldwide government policy preference towards market-based instruments to solve water reallocation issues, including environmental management systems [10]. However, as water trading developed in response to the cap, most water trades derived from previously un-activated and un-used consumptive water licences. 
This reduced surplus flows in MDB river systems, placing further environmental pressure on the system. Consequently, this well-intentioned program greatly reduced the states' ability to meet sustainable resource management objectives, in some respects increasing their conflict resolution transaction costs.

A further issue was the property rights needed to affect reallocation between existing users in response to the cap restrictions. For easy trade, the transaction costs associated with searching, negotiating deals, establishing contracts and enforcing agreements had to be minimised. These objectives resulted in strong property rights for consumptive users, which left little scope for new environmental rights. This was especially the case where their creation would reduce opportunities for economic returns from irrigation and industrial activity. Consequently, the environment had to share what remained of reduced in-stream flows. Thus, largely ineffective state water-sharing arrangements for environmental flow provision in the context of detrimental cap outcomes - as well as market-based pressures for strong property rights to achieve effective water trade between consumptive users - have perversely resulted in significant barriers to environmental water reallocation in the MDB. So, despite significant investments in water reform - estimated at more than $\$ 20$ billion [11] - inertia overshadowed the transfer of water to the environment in the MDB. This inertia continued for several years until severe drought effects either resulted in the suspension of water sharing plans altogether or the prioritisation of consumptive rights ahead of regulated environmental flow requirements [12]. These actions spurred the federal government to consider Basin Plan arrangements that would include SDLs well above the cap provisions - as well as a new round of transaction cost commitments.

The above discussion highlights unintended consequences of past MDB water reform decisions, as well as the significant level of transaction costs experienced to date. Using TCT approaches to examine MDB water reform transaction costs suggests many categories (i.e. research and information gathering, enactment of water laws, support and administrative services, and design and implementation phases) involve static transaction costs, which would entail significant further costs to reverse. Reversal transaction costs might mainly comprise conflict resolution expenses, given existing animosity between federal and MDB state governments. However, continuing state animosity toward Basin Plan structures as proposed - given credibility from agitation by stakeholders such as irrigation and environmental groups - threatens to result in significant transaction costs across all TCT categories. Obviously, reallocation of MDB water to the environment will be difficult to achieve in the absence of acceptable, effective and efficient Basin Planning and institutional support-structures. We therefore turn to the TCA cost-minimisation approach to help us identify alternative Basin Planning and institutional support structures to apply in the MDB context.

\subsection{MDB water reform using TCA analysis}

Transactions occur with the transfer of goods or services - or in this case the reallocation of resources between uses. In Williamson's TCA the following proposition applies: institutional structures possessing smoother transaction cost- 
economising properties will eventually displace those with greater frictions. This may not occur when economising would result in the loss of valued objectives by one of the parties to a transaction, such as political power or gain (Williamson 1981), but may be of interest in the context of state versus federal control under the proposed Basin Plan arrangements. In its evaluative role, TCA principally assumes that the transactors have bounded rationality (i.e. a curtailed capacity to evaluate all options or to obtain and consider all information) and a preference toward opportunism where possible (i.e. if parties can seek to benefit themselves at the expense of other transactors, they will). Based on these assumptions TCA examines the comparative costs of planning, adapting and monitoring task completion across a series of defined transaction dimensions under alternative institutional structures. Institutional arrangements establish the basis for market or administrative control over water resources, while the principle dimensions of transactions include uncertainty, frequency of exchange, specificity and the degree to which transfers involve transaction specific investments [13]. When compared to property rights, the assumed effect of Williamson's transaction dimensions on transaction costs may be less important in natural resource or environmental policy analysis. However, examination of the Basin Plan through Williamson's TCA lens is useful for measuring and evaluating policy design based on transaction cost types.

Table 1: Examples of TCA dimensions in the MDB.

\begin{tabular}{|c|c|}
\hline TCA Dimension & MDB Examples: \\
\hline $\begin{array}{l}\text { Uncertainty: the extent that } \\
\text { future contingences are unknown } \\
\text { or incalculable, such that } \\
\text { decision-makers are unable to } \\
\text { predict, plan and adapt } \\
\text { transaction exchange. }\end{array}$ & $\begin{array}{l}\text { Uncertainty provides scope for opportunistic behaviour. } \\
\text { Consumptive users' \& suppliers' uncertainty examples } \\
\text { include seasonal rainfall and evaporation rates. } \\
\text { Environmental users' uncertainty includes long-term base } \\
\text { in-stream flow requirements. }\end{array}$ \\
\hline $\begin{array}{l}\text { Frequency: refers to the level of } \\
\text { buyer activity in the market and } \\
\text { the characteristics of investments } \\
\text { made by suppliers to meet buyer } \\
\text { demand. }\end{array}$ & $\begin{array}{l}\text { Transactions conducted by consumptive and environmental } \\
\text { users requiring recurrent and usually costly investments to } \\
\text { transact. Examples include storage infrastructure } \\
\text { construction, supply channels and drains, flow control and } \\
\text { off-take equipment, system operation and maintenance costs } \\
\text { etc. }\end{array}$ \\
\hline $\begin{array}{l}\text { Specificity: relates to the extent } \\
\text { that resources (assets) required } \\
\text { for transactions can be redeployed } \\
\text { without reducing their productive } \\
\text { value [6]. }\end{array}$ & $\begin{array}{l}\text { Generally, three types of asset specificity are possible: } \\
\text { - Site-specificity - proximate location of resources such } \\
\text { that transport costs are economised. } \\
\text { - Physical asset specificity - specialised processes or } \\
\text { resources to produce outcomes. } \\
\text { - Human asset specificity - improvements arise from } \\
\text { learning by doing. }\end{array}$ \\
\hline $\begin{array}{l}\text { Transaction specific } \\
\text { investment: occurs where i) } \\
\text { sellers cannot transfer output } \\
\text { intended for one buyer to another } \\
\text { without difficulty, and ii) where } \\
\text { buyers cannot easily substitute } \\
\text { alternative products to achieve } \\
\text { outcomes. }\end{array}$ & $\begin{array}{l}\text { All water users in the MDB: } \\
\text { are unable to substitute alternative products } \\
\text { undertake specific investment to their operation } \\
\text { enter into transactions that, once enacted, are } \\
\text { Such transfereable }\end{array}$ \\
\hline
\end{tabular}


Table 1 provides simple definitions for each of Williamson's TCA dimensions and relevant examples drawn from the MDB. Of importance is the uncertainty surrounding the exact volume of water required to provide continuous MDB base in-stream flows [2] so that ecological functions such as fish movement, riparian vegetative growth, oxygenation and suspended sediments can all be managed. Some authors estimate that extraction levels above two-thirds of annual average inflows are unsustainable; but most agree that continuous minimum base flows are required to sustain ecosystems and biodiversity [14]. In addition to base flows, seasonal freshes to connect habitats and provide cues for breeding events and occasional flood events to clear away algal/water weed stocks, dilute toxin deposits and sustain ephemeral wetlands are required to mimic certain natural seasonal occurrences.

Where the transaction dimensions outlined in Table 1 are present, especially under the uncertainty related to MDB consumptive and environmental requirements, Williamson suggests that market institutions be applied to deliver standardised goods. If required, the market institution can be surrounded by an 'elaborate governance apparatus facilitating more adaptive, sequential decision making for non-standardised transaction' [5, p. 254], wherein bilateral structures give way to unified institutions. In Australia moves toward integration between regulatory and market instruments have taken place to shift farming into sustainable systems, but further work in this area may be necessary (as outlined below).

A unified institutional approach to water transfers between consumptive and environmental applications in the MDB would comprise the use of market transactions to provide permanent base in-stream environmental flows assuming such flow requirements have been established - with periodic flood and flush events being provided through statutory or administrative approaches facilitated by governments. While such a unified institutional approach might suggest a useful structure for the Basin Plan, this overlooks obvious market failure. This occurs particularly in regard to the historic lack of well-defined and enforced environmental property rights, the clear prevalence of different classes of rights, poor transferability between the two classes, information asymmetry and the propensity to sacrifice one class of rights in favour of the other [15]. The Basin Plan issue therefore requires further analysis.

\section{Contract-path analysis}

Establishing SDL limits for river systems under a Basin Plan represents only one part of the process. Enforcing prospective contracting arrangements and managing scarce water supplies to optimise the benefits from environmental flow applications constitutes a larger continuous issue [4]. Assuming that the SDLs equate to the minimal requirement for in-stream base environmental flows, Basin Plan structures must be developed that reduce the transaction costs of providing these flows. A basis for structuring alternate Basin Plan approaches may benefit from an expansion of Williamson's TCA toward more detail contract-path analyses. Under orthodox economic assumptions markets require 
well defined property rights that are uniformly apparent such that courts will enforce transfer contracts [16]. But, many contradictions to these assumptions can be found in water transfers. Within the TCA framework, market analysis is superseded by analysis of transactions and alternative institutional arrangements, including inter-temporal contracting [17]. The TCA contract-path model for selecting institutional structures (Figure 1) pivots: first on an assessment of hazards $(\mathrm{H})$; and second on an assessment of the sureties or safeguards (S) required in the transaction. Where contractual hazards are negligible $(\mathrm{H}=0)$, the institutional structure will be simple, taking the form of an unassisted market (Node A). The current choice of institutional structure for MDB water, where consumptive rights are prioritised, reflects this arrangement.

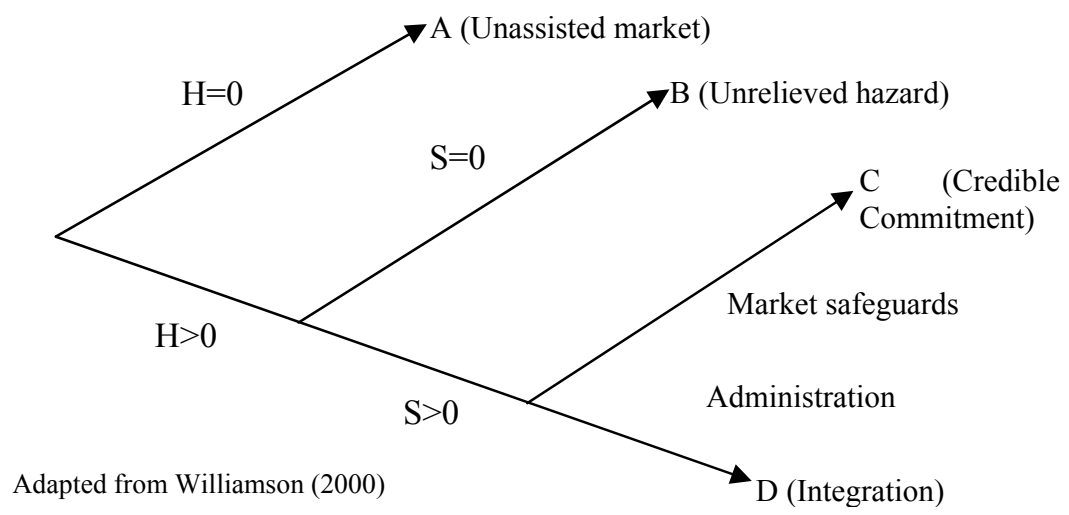

Figure 1: $\quad$ Simple contracting schema.

Markets have been established to transfer water between users, under the implicit assumption that hazards associated with state government nonenforcement of environmental contract rights are negligible - although this is clearly not the case. However, as the Australian government moves to recognise the implicit environmental hazards - e.g., weak property rights - and attempts to impose an agenda of environmental contract enforcement over this situation through the Basin Plan, it begins a move towards other institutional structures. Water extracted and used for productive (e.g., cropping) or environmental benefit (e.g. flood or flush event flows) locks suppliers and buyers into bilateral agreements to deliver and use the water at specific sites for specific purposes. In a simple model, the deployed water would not re-enter the system. Conversely, in-stream environmental base flows could be diverted and redeployed without sufficient property right protection, since its original application purpose could not be enforced. In essence, the current structural arrangements represent government or public policy failure. This needs to be remedied in future institutional approaches associated with the Basin Plan. As shown in Figure 1, moving toward more complex institutional structures involves the addition of safeguards, reduced incentive intensity and added bureaucratic costs. For example, to overcome weak property rights, accommodate potential climate 
change impacts and address base ecosystem health risk issues we may determine that environmental users will require more security (safeguards) in future. Assume also that consumptive users are already experienced with, or in future will have to adapt toward, higher volatility in water supply and market transfers. This may constitute a move toward Node $\mathrm{C}$ where warranties may ensure that the full spectrum of base, freshes and overbank flows are provided. Further examination of these institutional shifts is provided in the following sections.

\section{Evaluating alternate Basin plan structures}

Basin Plan institutional alternatives can be generally categorised into: i) base environmental flow provision established purely on market transactions or on a mixture of market transactions and prioritised rights; and ii) occasional flood/flush provisions utilising only entitlement purchase and storage or the incorporation of allocation trade and targeted water applications.

\subsection{Permanent base environmental flow structural alternatives}

Permanent provision of base environmental flows implicitly assumes that the Australian government accepts the hazards associated with non-delivery $(\mathrm{H}>0)$. It also assumes that historical safeguards have been either non-existent or incomplete - that is, efficient and effective transfers from consumptive water users to the environment have been insufficient to address hazards. Therefore, the need for safeguards remains in the context of MDB water transfers $(S>0)$ and the evaluation of alternatives is premised upon the choice between Node $\mathrm{C}$ ( $\mathrm{a}$ credible commitment structure using market safeguards) and Node D (an integration structure using administrative safeguards).

\subsubsection{Pure market transaction focus}

A Basin Plan structure incorporating market safeguards would involve federal government sourcing of permanent base in-stream environmental water flow supplies through the acquisition of either allocation or entitlement rights. Allocation rights would be acquired every season, and the number of transactions required would fluctuate from season to season, dependent upon prevailing supply conditions. Such a structure would result in significant information asymmetry around consumptive and environmental use strategies. It would also maintain weak property rights for base environmental flows given the potential for in-stream redeployment during a season, as well as potentially inadequate site-specificity between source and use locations with possibly higher transportation costs. Additionally, multiple negotiation and legal transaction costs each season, recurrent government intervention in the market creating externalities for traditional users, and the potential for windfall gains and losses among consumptive allocation traders would be probable.

\subsubsection{Market transaction focus and prioritised environmental rights}

Alternatively, if the Australian government acquired entitlement rights through the market in sufficient quantity (presumably over a short-term timeframe) to 
match the SDL requirements, this would reduce strategic information considerations to those associated only with environmental managers. Targeted entitlement acquisition would provide the potential for better site specificity between source and use locations via strategic acquisition of rights with lower transport costs, and reduce the total amount of negotiation and legal transaction costs necessary to secure the water. Finally, the strategy would limit the level and scope of intervention required in the market, given the smaller volume of MDB trade volume in the entitlement market compared to the allocation market.

Thus, a market safeguard structural option using entitlement acquisition appears to provide significant transaction cost reductions and a more efficient approach. However, the property rights issue would still need to be addressed the possibility for redeployment of in-stream environmental flows would still be present. If these acquired entitlement rights were permanently removed from the consumptive pool and provided with statutory priority $-100 \%$ allocation in $100 \%$ of seasons before other users are permitted to a share of the remainder of flows - that would serve to reduce redeployment of in-stream base environmental flows, therein securing property rights. The argument above suggests that, in the provision of base environmental flows, an efficient transaction cost-minimising Basin Plan structure would employ short-term market intervention to secure entitlement rights sufficient to meet the SDLs (Node C), permanently removing those rights from the consumptive pool. This Basin Plan would also require statute-based prioritisation of these separated environmental rights under an administrative structure (Node D), to provide base flows with $100 \%$ allocation every season. A further benefit is that remaining consumptive users would be able to adjust to share restrictions and fluctuating seasonal water requirements through the market, without the threat of continued government intervention.

\subsection{Occasional flood/flush environmental flow structural alternatives}

However, in order that the Basin Plan mimics all environmental flow events occasional flood or flush events will also be required. Once again, it is assumed that hazards are implied $(\mathrm{H}>0)$, and that safeguards will be required $(\mathrm{S}>0)$ to ensure compliance under the Basin Plan arrangements.

\subsubsection{Entitlement and storage}

One option for Basin Plan institutional arrangements could be to apply market safeguards within the structure itself. Again, market alternatives correspond to the choice between water entitlement and allocation trade products. Entitlement acquisition for occasional flood event provision would entail purchasing and storing large volumes of water. To match uncertain site specificity requirements water would have to be stored in multiple locations at significant costs. Sufficient water would need to be purchased and stored to encompass storage evaporation and seepage losses over the period between flush flows. If the location of flood or flush requirements were distant from the storage facility significant transport costs and losses in water volume before reaching the environmental site(s) would arise. The space required to store such water over 
long intervals would therefore impose significant third-party effects and costs on other users of the infrastructure. Finally, since the scientific basis for flood and flush event $\mathrm{s}$ is subject to future alteration - resulting in poor locational matches between environmental sites and water entitlement licenses, the Australian government might be tempted to trade those rights periodically, with inherent subsequent impacts upon environmental flow arrangements, sunk environmental work investments to delivery that water and increased market transaction costs. Substantial transaction costs associated with entitlement-based flood/flush flow institutional structures could also be incurred if the states, as owners and managers of the storage infrastructure, decided to obfuscate the flood/flush environmental transfers for political, social or economic gain. The probability of this scenario could, of course, be minimised if the Australian government acquired infrastructure and water resources from the states in order to deliver the water (and the national environmental agenda outcomes) with managerial certainty. However, it is obvious that infrastructure acquisition would incur extremely large transaction (in this case budgetary) costs. The Australian government would thus optimise its arrangements by avoiding extensive legal negotiation costs with the states, as well as the sizeable resource, infrastructure acquisition and on-going management and maintenance costs required to operate the system - which currently represent the states' historical sunk costs. The idea of sunk costs is key to rational water and environmental policy; any Basin Plan based on averages cannot take account of sunk costs, whether they are environmental or economic [18]. It would be more efficient for the Australian government to invest in appropriate incentives to manage the potential state issues and conflicts and to achieve some form of principal-agent agreement.

\subsubsection{Occasional allocation trade and targeted application}

Alternatively, if the Basin Plan market safeguard institutional structure focused on occasional purchase of water allocations via markets, the storage and thirdparty impact costs would be negligible for the same environmental outcomes. It is also probable that allocation purchasing would take place after significant high flow events when the allocation market would be well supplied, and prices would reflect this outcome. Targeted purchasing in this manner would provide lower transport and market transaction costs overall. Further, productive and economic losses for the season would be minimal due to surplus water in the system and government market intervention effects (i.e. reduced consumptive user adjustment capacity) would be minimised. For occasional flood or flush event provision it seems the use of market safeguards incorporating infrequent allocation purchasing (Node C) offers an efficient alternative structure for the MDB Basin Plan.

\section{Discussion}

At the start of this paper two conflicts associated with the Australian watersharing process were introduced. The first involved the need to transfer water away from consumptive uses toward environmental flow provision, and the 
economic trade-offs that this process entails. Previous public policy arrangements have failed to address this conflict, and drought has subsequently emphasised both the need for environmental transfers and weaknesses of past institutional approaches. Partly to address this problem, the Australian government has embarked upon a strategy of purchasing entitlements in the market to reduce the eventual gap between ex ante and ex post SDL reductions and the residual consumptive pool requirements. It seems clear now that any consumptive entitlements purchased for the environment will retain their original rights status, and there is little argument for changing their priority as that would erode consumptive rights without compensation [15]. In line with National Water Initiative (NWI) conditions, the Basin Plan could be formatted such that all consumptive users have their entitlements cut pro rata to deliver immediate water for the environment. However, such an approach has already been ruled out by the Australian government [19]. Therefore, given a high probability of political fallout and significant potential economic impacts in the MDB from across-the-board reductions in entitlements, it seems unlikely that the Australian government would follow such a strategy. On that basis, an Australian entitlement acquisition strategy provides an appropriate compensatory measures through the market and welfare transfers, while achieving the primary objective of drawing the consumptive pool down to reduce the risk of future conflicts between users. The current federal MDB planning approach appears to be consistent with our TCA analysis assessment for an inefficient Basin Plan. That is, government intervention in the market to acquire entitlements given that the future property status of these rights remains uncertain. Addressing this uncertainty represents a major challenge for the future Basin Plan if it is to provide more efficient transfers of water between consumptive and environmental rights. An argument exists for environmental rights established under the Basin Plan process to receive higher priority. We would argue that this is imperative if the Basin Plan structure is to achieve its objectives efficiently and effectively. More important, however, is the Australian government's approach to provision of occasional flood or flush event flows. Analysts have already flagged a need in the MDB to incorporate allocation water and other sophisticated products into the portfolio of arrangements aimed at dealing with environmental flow provision [20]. Those recommendations would be supported by this paper's TCA analysis, which suggests that occasional acquisition of allocation water on the market provides an efficient structure for occasional flood or flush events. However, while current arrangements under the 2004 NWI agreements provide scope for the Australian government to operate its environmental water management in this way [21], at present such a strategy does not appear to have practical support from federal environmental water managers or the relevant state agencies. Once again, a challenge for the final Basin Plan is to address this institutional deficiency. Changing focus toward the second conflict introduced at the start of the paper regarding state and federal government interdependencies, the paper's TCA analysis has highlighted several issues of importance for the future Basin Plan. For example, there is considerable potential for the national environmental agenda to be undone by state 
opportunism. Equally, the Australian government needs to recognise the potential political and social losses that a reduction in power or income from infrastructure utility would represent, as well as the potential social adjustment costs that would be triggered under the Basin Plan. Overall, transaction costs represent a significant barrier to self-governance and their minimisation will result in a higher probability of federal/state cooperative success. On that basis it may be necessary to introduce a range of appropriate incentives that not only compensate the states for losses incurred through the Basin Plan process, but which also help to ensure compliance. Such arrangements were originally created and provided for under national competition policy, but seem to have fallen out of favour.

\section{Conclusions}

The risks of inappropriate basin-wide planning institutional structures include: intensifying conflict between consumptive and environmental users; extending the government and public policy failure already evident in MDB water-sharing arrangements; increasing the likelihood of politically unpalatable pro rata consumptive reductions; and amplified market transaction costs in future years.

However, within the context of dynamic transaction costs and institutional analysis there is scope to correctly structure the MDB Basin Plan to efficiently reallocate water transfers from consumptive users toward permanent environmental base-flows, freshes and occasional flood environmental flows. This paper has used the TCT categorisation approach suggested by McCann \& Easter to identify the types of transaction costs associated with alternative Basin Plan structures and Williamson's TCA framework to evaluate alternative MDB Basin Plan institutional structures. As such, we have identified a potential set of efficient approaches. While the current Australian government focus upon purchasing entitlements represents an important first step, there is still considerable ambiguity present in the Basin Plan that needs to be addressed. In particular, the TCA analysis presented here highlights a need for the Australian government to break away from previous public policy failures, as well as the path dependent nature of state water-sharing plans, to deliver prioritised environmental rights in the southern MDB.

\section{References}

[1] MDBA, Proposed Basin Plan - A revised draft, 2012, Murray-Darling Basin Authority: Canberra.

[2] NWC, Sustainable levels of extraction: National Water Commission position statement, 2010, National Water Commission: Canberra.

[3] Coggan, A., S.M. Whitten, and J. Bennett, Influences of transaction costs in environmental policy. Ecological Economics, 2010. 69(9): p. 1777-1784.

[4] McCann, L. and K.W. Easter, A framework for estimating the transaction costs of alternative mechanisms for water exchange and allocation. Water Resources Research, 2004. 40(9): p. W09S09. 
[5] Williamson, O., Transaction-cost economics: the governance of contractual relations. Journal of Law and Economics, 1979. 22(2): p. 233261.

[6] Williamson, O., Transaction cost economics: how it works; where it is headed. De Economist, 1998. 146: p. 23-58.

[7] Hanemann, W.M., The economic conception of water, in Water crisis: Myth or reality?, P. Rogers and R. Llamas, Editors. 2006, Taylor and Francis: New York.

[8] COAG, Council of Australian Governments communiqué, 1994: 25th February 1994.

[9] MDBC, Murray-Darling Basin Cap on diversions: Water year 1997/98 Striking the balance, 1998, Murray-Darling Basin Commission: Canberra.

[10] Jordan, A., R. Wurzel, and A. Zito, The rise of 'new' policy instruments in comparative perspective: Has governance eclipsed government? Political Studies, 2005. 53(3): p. 477-496.

[11] Garrick, D., et al., Water markets and freshwater ecosystem services: Policy reform and implementation in the Columbia and Murray-Darling Basins. Ecological Economics, 2009. 69(2): p. 366-379.

[12] Tan, P.-L., Irrigators come first: conversion of existing allocations to bulk entitlements in the Goulburn and Murray catchments, Victoria. Environmental \& Planning Law Journal, 2001. 18(2): p. 154-187.

[13] Mayer, K.J., Construct validity and other empirical issues in transaction cost economics research. Research Methodology in Strategy and Management, 2009. 5: p. 213-236.

[14] Hart, B. and C. Pollino, Bayesian modelling for risk-based environmental water allocation, 2009, Waterlines Report, National Water Commission: Canberra.

[15] Loch, A., H. Bjornlund, and R. McIver, Achieving targeted environmental flows: An evaluation of alternative allocation and trading models under scarce supply - lessons from the Australian reform process. Environment \& Planning C: Government \& Policy, 2011. 29(4): p. 745-760.

[16] Coase, R., The nature of the firm. Economica N.S., 1937. 4: p. 386-405.

[17] Williamson, O., Economics and organisation: A primer. California Management Review, 1996. 38(2): p. 131-146.

[18] Watson, A. and T. Cummins, Historical influences on irrigation and water policy in the Murray-Darling Basin, in Network: a publication of the ACCC for the Utility Regulators' Forum2010, Australian Competition and Consumer Commission: Canberra. p. 7.

[19] The Senate, Implications for long-term sustainable management of the Murray-Darling Basin system, 2009, Rural and Regional Affairs and Transport References Committee: Canberra.

[20] Productivity Commission, Market mechanisms for recovering water in the Murray-Darling Basin, Final report, in Productivity Commission2010, Productivity Commission: Canberra.

[21] COAG, Intergovernmental agreement on a National Water Initiative, 2004: Canberra. 